\title{
On Certain Discrete Inequalities and Their Continuous Analogs
}

\section{Allen M. Pfeffer ${ }^{1}$}

(May 24, 1966)

\begin{abstract}
The purpose of this paper is to find inequalities between the $L^{2}$-norms of a function and its $k$ th and $m$ th derivatives.

Key Words: Inequalities, norms, Wirtinger.
\end{abstract}

\section{Introduction}

In $1955[2]^{2}$ Fan, Taussky, and Todd discovered discrete analogs of certain integral inequalities involving functions and their derivatives. They considered inequalities of the Wirtinger type: $\int_{0}^{2 \pi} x(t)^{2} d t \leqslant \int_{0}^{2 \pi} x^{\prime}(t)^{2} d t$, where $x$ has period $2 \pi$ and $\int_{0}^{2 \pi} x(t) d t=0 . \quad$ By taking limits they were able to derive continuous inequalities by matrix techniques and avoided the differential equations of the calculus of variations. We have attempted to generalize the techniques of [2] to polynomials in the derivatives of $x$. We have also considered analogs of inequalities of Müller [5] and Redheffer [7] and have used these inequalities to derive a necessary and sufficient condition on ordered pairs of numbers so that the first number is the square norm of the $k$ th derivative of some periodic function and the second number is the square norm of the $m$ th derivative of the same periodic function. This last result is the $L_{2}$ analog of a result of Kolmogoroff [4] on the uniform norm.

\section{General Technique}

The following is the basic technique of Fan, Taussky, and Todd [2] and will be used to derive most of our inequalities. Let $S$ be a real symmetric $n \times n$ matrix with eigenvalues $\lambda_{1} \geqslant \lambda_{2}$ $\geqslant \ldots \geqslant \lambda_{n}$ and let $v_{1}, v_{2}, \ldots, v_{n}$ be the corresponding linearly independent eigenvectors:

$$
S v_{i}=\lambda_{i} v_{i}(i=1,2, \ldots, n) .
$$

If $P$ is a polynomial with real coefficients, then $P(S)$ is a real symmetric $n \times n$ matrix and we know that $P(S)$ has eigenvalues $P\left(\lambda_{1}\right), P\left(\lambda_{2}\right), \ldots ., P\left(\lambda_{n}\right)$ with corresponding eigenvectors $v_{1}, v_{2}, \ldots ., v_{n}$ so that $P(S) v_{i}=P\left(\lambda_{i}\right) v_{i}(i=1,2, \ldots ., n)$.

By a well-known property of symmetric matrices

$$
\min _{\left[1 \leqslant i \leqslant n\left\{P\left(\lambda_{i}\right)\right\}\right] \cdot(x, x) \leqslant(x, P(S) x) \leqslant\left[1 \leqslant i \leqslant n\left\{P\left(\lambda_{i}\right)\right\}\right] \cdot(x, x)}
$$

for every $n$-vector $x$, where $(x, y)=x^{T} y$ for $n$-vectors $x$ and $y$.

Now we must have

$$
\inf _{\left[\lambda_{n} \leqslant t \leqslant \lambda_{1}\{P(t)\}\right] \leqslant\left[1 \leqslant n\left\{P\left(\lambda_{i}\right)\right\}\right]}^{\min }
$$

\footnotetext{
*An invited paper. This work was supported by the National Science Foundation and the Office of Naval Research. Part of this was included in a California Institute of Technology Ph. D. thesis (1965)

${ }^{1}$ Present address: California Institute of Technology.

${ }^{2}$ Figures in brackets indicate the literature references at the end of this paper.
} 
and

$$
\sup _{\left[\lambda_{n} \leqslant t \leqslant \lambda_{1}\{P(t)\}\right] \leqslant\left[1 \leqslant i \leqslant n\left\{P\left(\lambda_{i}\right)\right\}\right]} \max
$$

hence

$$
\inf _{\left[\lambda_{n} \leqslant t \leqslant \lambda_{1}\{P(t)\}\right] \cdot(x, x) \leqslant(x, P(S) x) \leqslant\left[\lambda_{n} \leqslant t \leqslant \lambda_{1}\{P(t)\}\right] \cdot(x, x)}^{\sup }
$$

for every $n$-vector $x$.

We note that equality is possible in the last expression if and only if $P\left(\lambda_{i}\right)=\lambda_{n} \leqslant t \leqslant \lambda_{1}\{P(t)\}$ inf

for some $i$ between 1 and $n$ or $P\left(\lambda_{i}\right)=\lambda_{n} \leqslant t \leqslant \lambda_{1}\{P(t)\}$ for some $i$ between 1 and $n$. If equality does occur then the set of extremal vectors must be the space spanned by the eigenvectors corresponding to $\lambda_{i}$.

For reasons of simplicity we will only consider vectors with real components and real symmetric matrices, in all cases the extension to complex vectors and Hermitian matrices will be apparent.

\section{Periodic Boundary Conditions}

Because of the absence of troublesome boundary conditions the periodic case is easiest to handle. We may periodically extend any $n$-vector $x=\left(x_{1}, x_{2}, \ldots, x_{n}\right)^{T}$ by setting $x_{i+r n}=x_{i}$ for $i=1,2, \ldots, n$ and $r$ any integer.

DEFINITION: If $x$ is a periodically extended $n$-vector then for $m=0,1,2, \ldots$

$$
x^{(m)}=\left(\Delta^{m} x_{1}, \Delta^{m} x_{2}, \ldots, \Delta^{m} x_{n}\right)^{T},
$$

where

$$
\Delta^{m} x_{i}=\sum_{r=0}^{m}(-1)^{m-r}\left(\begin{array}{c}
m \\
r
\end{array}\right) x_{i-[m / 2]+r} \quad(i=1,2, \ldots, n) .
$$

We call $x^{(m)}$ the $m$ th difference of the $n$-vector $x$.

It is clear that $x^{(r+s)}=\left(x^{(r)}\right)^{(s)}$ for $r, s=0,1,2, \ldots$.

The following lemma, which is crucial for our inequalities, was proved by Fan-Taussky-Todd [2] for $m=0,1,2$.

LemмA 1. If $\mathrm{x}$ is a periodically extended $\mathrm{n}$-vector, then $\left(\mathrm{x}^{(\mathrm{m})}, \mathrm{x}^{(\mathrm{m})}\right)=\left(\mathrm{x}, \mathrm{P}^{\mathrm{m}} \mathrm{x}\right)(\mathrm{m}=0,1,2, \ldots)$, where $\mathrm{P}$ is the $\mathrm{n} \times \mathrm{n}$ symmetric circulant

$$
\left[\begin{array}{rrrrrrr}
2 & -1 & 0 & \cdot & \cdot & \cdot & -1 \\
-1 & 2 & -1 & \cdot & \cdot & \cdot & 0 \\
\cdot & \cdot & \cdot & & & \\
\cdot & \cdot & \cdot & & & \\
\cdot & \cdot & \cdot & & & & \cdot \\
-1 & 0 & \cdot & . & . & -1 & 2
\end{array}\right]
$$


Proof:

$$
P x=\left[\begin{array}{c}
-x_{n}+2 x_{1}-x_{2} \\
\cdot \\
\cdot \\
-x_{1}+2 x_{n}-x_{n-1}
\end{array}\right]=-x^{(2)} \text {, hence } P x^{(j)}=-x^{(j+2)} \text {. }
$$

By partial summation

$$
\left(x, x^{(2)}\right)=\sum_{k=1}^{n} x_{k}\left(x_{k-1}-2 x_{k}+x_{k+1}\right)=-\sum_{k=1}^{n}\left(x_{k+1}-x_{k}\right)^{2}=-\left(x^{(1)}, x^{(1)}\right),
$$

yielding

$$
\left(x^{(j)}, P x^{(j)}\right)=\left(x^{(j+1)}, x^{(j+1)}\right) .
$$

Thus if $m$ is even we have

$$
\left(x^{(m)}, x^{(m)}\right)=\left(P^{\frac{m}{2}} x, P^{\frac{m}{2}} x\right)=\left(x, P^{m} x\right),
$$

while if $m$ is odd

$$
\left(x^{(m)}, x^{(m)}\right)=\left(x^{(m-1)}, P x^{(m-1)}\right)=\left(P^{\frac{m-1}{2}} x, P \cdot P^{\frac{m-1}{2}} x\right)=\left(x, P^{m} x\right) .
$$

Rutherford [8] has shown that $P$ has eigenvalues $4 \sin ^{2}\left(\frac{k \pi}{n}\right)(k=1,2, \ldots, n)$, hence $\lambda_{n}=0$, $\lambda_{n-1}=\lambda_{n-2}=4 \sin ^{2}\left(\frac{\pi}{n}\right), \ldots, \lambda_{1}=4 \sin ^{2}\left(\left[\frac{n}{2}\right] \frac{\pi}{n}\right)$. The eigenvector corresponding to $\lambda_{n}$ is $(1,1, \ldots, 1)^{T}$.

At this point we have two alternatives open to us. If $F$ is a polynomial with real coefficients then we may use the method that we have described in section 2 or else we may also add the auxiliary condition $\sum_{k=1}^{n} x_{i}=0$, which is equivalent to the requirement $(x, e)=0$, where $e=(1$, $1, \ldots, 1)^{T}$. Since $e$ is the eigenvector corresponding to $\lambda_{n}=0$, the auxiliary orthogonality condition implies that we need only take our maximum and minimum over $\left\{F\left(\lambda_{1}\right), F\left(\lambda_{2}\right), \ldots, F\left(\lambda_{n-1}\right)\right\}$.

The following example should illustrate the differences in the two approaches.

Let $P(t)=t^{m}$ for $m \geqslant 1$. Since $P(t)$ is increasing for nonnegative $t$ and since $0=\lambda_{n}<\lambda_{n-1}$ $\leqslant \ldots \leqslant \lambda_{1}$, we have $1 \leqslant i \leqslant n\left\{P\left(\lambda_{i}\right)\right\}=0$ and $1 \leqslant i \leqslant n-1\left\{P\left(\lambda_{i}\right)\right\}=P\left(\lambda_{n-1}\right)=4^{m} \sin ^{2 m}\left(\frac{\pi}{n}\right)$.

Thus if $x$ is a periodically extended $n$-vector then we have the trivial inequality $\left(x^{(m)}, x^{(m)}\right)$ $\geqslant 0(x, x)=0$; however if we add the auxiliary condition $\sum_{i=1}^{n} x_{i}=0$, then we obtain $\left(x^{(m)}, x^{(m)}\right) \geqslant 4^{m}$ $\sin ^{2 m}\left(\frac{\pi}{n}\right)(x, x)$.

We note that the above inequalities are best possible and we include a discussion of the possibility of equality. For brevity this will be the only case where we discuss equality in the discrete case.

If $\left(x^{(m)}, x^{(m)}\right)=0$, then $x$ must be in the subspace spanned by the eigenvectors corresponding to $\lambda_{n}=0$. Thus $x=a \cdot(1,1, \ldots, 1)^{T}$, where $a$ is a real number. 
If $\sum_{i=1}^{n} x_{i}=0$ and $\left(x^{(m)}, x^{(m)}\right)=4^{m} \sin ^{2 m}\left(\frac{\pi}{n}\right) \cdot(x, x)$, then $x$ must be in the subspace spanned by the eigenvectors corresponding to $\lambda_{n-1}=\lambda_{n-2}=4 \sin ^{2}\left(\frac{\pi}{n}\right)$. It is known, [2], that this subspace is spanned by the vectors $u=\left(u_{1}, u_{2}, \ldots, u_{n}\right)^{T}$ and $w=\left(w_{1}, w_{2}, \ldots, w_{n}\right)^{T}$, where $u_{j}=\cos \left(\frac{2 \pi j}{n}\right)$ and $w_{j}=\sin \left(\frac{2 \pi j}{n}\right)$. Thus $x=a \cdot u+b \cdot w$, where $a$ and $b$ are real numbers.

Hence we have established the following extension of Theorem 10 of [2].

THEOREM 1. If $\mathrm{x}$ is a periodically extended $\mathrm{n}$-vector and if $\sum_{\mathrm{i}=1}^{\mathrm{n}} \mathrm{x}_{\mathrm{i}}=0$, then

$$
\left(x^{(m)}, x^{(m)}\right) \geqslant 4^{m} \sin ^{2 m}\left(\frac{\pi}{n}\right) \cdot(x, x) .
$$

Equality holds if and only if $\mathrm{x}$ is the periodic extension of a vector of the form $\mathrm{a} \cdot \mathrm{u}+\mathrm{b} \cdot \mathrm{w}$.

Corollary 1.1. If $\mathrm{x}(\mathrm{t}) \in \mathrm{C}^{\mathrm{m}}[\mathrm{a}, \mathrm{b}], \mathrm{x}(\mathrm{t})$ has period $\mathrm{b}-\mathrm{a}$, and $\int_{\mathrm{a}}^{\mathrm{b}} \mathrm{x}(\mathrm{t}) \mathrm{dt}=0$, then

$$
\int_{a}^{b}\left\{x^{(m)}(t)\right\}^{2} d t \geqslant\left(\frac{2 \pi}{b-a}\right)^{2 m} \int_{a}^{b}\{x(t)\}^{2} d t
$$

ProOF:

If we let $\Delta=\frac{b-a}{n+1}$ and $y_{i}=x\left(t_{i}\right)-\frac{1}{n} \sum_{j=1}^{n} x\left(t_{j}\right)$, where $t_{i}=a+i \Delta$, then

$$
\frac{\left(y^{(m)}, y^{(m)}\right)}{\Delta^{2 m}} \cdot \Delta \geqslant \frac{4^{m} \sin ^{2 m}\left(\frac{\bar{\pi}}{n}\right)}{\Delta^{2 m}} \cdot(y, y) \Delta .
$$

The result now follows when we let $n \rightarrow \infty$.

A careful inspection of the proof of Theorem 1 will show that we only used the periodic exten-

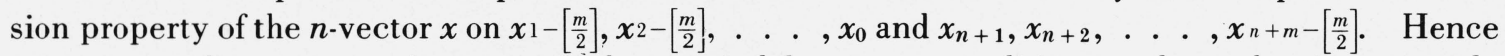
we may weaken our requirement $x(t)$ has period $b-a$ to a condition on the end points, namely $x(a)=x(b), x^{\prime}(a)=x^{\prime}(b), \ldots, x^{(m-1)}(a)=x^{(m-1)}(b)$.

Halperin and Pitt [3], Müller [5], Nirenberg [6], and Redheffer [7] have developed inequalities of the form:

$$
\int_{a}^{b}\left\{x^{\prime}(t)\right\}^{2} d t \leqslant \alpha \int_{a}^{b}\left\{x^{\prime \prime}(t)\right\}^{2} d t+H(\alpha) \int_{a}^{b}\{x(t)\}^{2} d t
$$

where $x(t) \in \mathrm{C}^{2}[a, b], \alpha>0$. Redheffer obtained the best possible value of $H(\alpha)$. We will now develop generalizations of the form:

$$
\int_{a}^{b}\left\{x^{(k)}(t)\right\}^{2} d t \leqslant \alpha \int_{a}^{b}\left\{x^{(m)}(t)\right\}^{2} d t+H_{k, m}(\alpha) \int_{a}^{b}\{x(t)\}^{2} d t
$$

$1 \leqslant k<m$ under the further restriction that $x(a)=x(b), x^{\prime}(a)=x^{\prime}(b), \ldots, x^{(m-1)}(a)=x^{(m-1)}(b)$. These inequalities will be established by taking limits of the appropriate discrete inequalities. 
Incidentally we observe that $H_{1,2}(\alpha)$ for our periodic case is much smaller than Redheffer's general value of $\frac{1}{\alpha}+\frac{12}{(b-a)^{2}}$.

If we let $P(t)=\theta^{k} t^{k}-\alpha \theta^{m} t^{m}$, then we wish to maximize $P(t)$ on $\left[\lambda_{n}, \lambda_{1}\right]=\left[0,4 \sin ^{2}\left(\left[\frac{n}{2}\right] \frac{\pi}{n}\right)\right]$. Since $P^{\prime}(t)=k \theta^{k} t^{k-1}-m \alpha \theta^{m} t^{m-1}$, if we assume that $\theta>0$ then the maximum value of $P(t)$ on $t \geqslant 0$ occurs at $t=\frac{1}{\theta}\left(\frac{k}{m \alpha}\right)^{1 / m-k}$ Thus $\lambda_{n} \leqslant t \leqslant \lambda_{1}\{P(t)\} \leqslant P\left(\frac{1}{\theta}\left\{\frac{k}{m \alpha}\right\}^{1 / m-k}\right)=\left(\frac{k}{m \alpha}\right)^{k / m-k}\left(1-\frac{k}{m}\right)$.

An inspection of the graph of $P(t)$ will yield the following cases:

If $\lambda_{1} \geqslant \frac{1}{\theta}\left(\frac{k}{m \alpha}\right)^{1 / m-k}$ then

$$
\sup _{n} \leqslant t \leqslant \lambda_{1}\{P(t)\}=P\left(\frac{1}{\theta}\left[\frac{k}{m \alpha}\right]^{1 / m-k}\right)=\left(\frac{k}{m \alpha}\right)^{k / m-k}\left(1-\frac{k}{m}\right)
$$

If $\lambda_{1} \leqslant \frac{1}{\theta}\left(\frac{k}{m \alpha}\right)^{1 / m-k}$ then

$\sup _{n} \leqslant t \leqslant \lambda_{1}\{P(t)\}=P\left(\lambda_{1}\right)=P\left(4 \sin ^{2}\left(\left[\frac{n}{2}\right] \frac{\pi}{n}\right)\right)$

$$
=4^{k} \theta^{k} \sin ^{2 k}\left(\left[\frac{n}{2}\right] \frac{\pi}{n}\right)\left\{1-4^{m-k} \theta^{m-k} \alpha \sin ^{2 m-2 k}\left(\left[\frac{n}{2}\right] \frac{\pi}{n}\right)\right\} .
$$

If $n$ is even then $P\left(\lambda_{1}\right)=4^{k} \theta^{k}\left\{1-4^{m-k} \theta^{m-k} \alpha\right\}$.

Hence we have the following result.

Tнеовем 2. If $\mathrm{x}$ is a periodically extended $\mathrm{n}$-vector, $\alpha$ and $\theta$ are positive constants, $1 \leqslant \mathrm{k}<\mathrm{m}$ then we have the following inequality:

$$
\theta^{\mathrm{k}}\left(\mathrm{x}^{(\mathrm{k})}, \mathrm{x}^{(\mathrm{k})}\right) \leqslant \alpha \theta^{\mathrm{m}}\left(\mathrm{x}^{(\mathrm{m})}, \mathrm{x}^{(\mathrm{m})}\right)+\left(\frac{\mathrm{k}}{\mathrm{m} \alpha}\right)^{\mathrm{k} / \mathrm{m}-\mathrm{k}}(1-\mathrm{k} / \mathrm{m})(\mathrm{x}, \mathrm{x}) .
$$

If $4 \leqslant \frac{1}{\theta}\left(\frac{\mathrm{k}}{\mathrm{m} \alpha}\right)^{1 / \mathrm{m}-\mathrm{k}}$, then we may improve the above inequality to:

$$
\theta^{\mathrm{k}}\left(\mathrm{x}^{(\mathrm{k})}, \mathrm{x}^{(\mathrm{k})}\right)-\alpha \theta^{\mathrm{m}}\left(\mathrm{x}^{(\mathrm{m})}, \mathrm{x}^{(\mathrm{m})}\right) \leqslant 4^{\mathrm{k}} \theta^{\mathrm{k}}\left\{1-4^{\mathrm{m}-\mathrm{k}} \theta^{\mathrm{m}-\mathrm{k}} \alpha\right\} \cdot(\mathrm{x}, \mathrm{x}) .
$$

Proof:

We note that

$$
4 \leqslant \frac{1}{\theta}\left(\frac{k}{m \alpha}\right)^{1 / m-k}
$$

certainly implies that

$$
4 \sin ^{2}\left(\left[\frac{n}{2}\right] \frac{\pi}{n}\right) \leqslant \frac{1}{\theta}\left(\frac{k}{m \alpha}\right)^{1 / m-k}
$$

and $P(t)$ is increasing on the interval $\left[0, \frac{1}{\theta}\left(\frac{k}{m \alpha}\right)^{1 / m-k}\right]$. 
If we take $\theta=\left(\frac{n+1}{b-a}\right)^{2}$ and let $n \rightarrow \infty$ then we obtain a continuous analog of Theorem 2 .

Corollary 2.1. If $\mathrm{x}(\mathrm{t}) \in \mathrm{C}^{\mathrm{m}}[\mathrm{a}, \mathrm{b}], 1 \leqslant \mathrm{k}<\mathrm{m}, \mathrm{x}(\mathrm{a})=\mathrm{x}(\mathrm{b}), \mathrm{x}^{\prime}(\mathrm{a})=\mathrm{x}^{\prime}(\mathrm{b}), \ldots, \mathrm{x}^{(\mathrm{m}-1)}(\mathrm{a})=\mathrm{x}^{(\mathrm{m}-1)}(\mathrm{b})$, and if $\alpha>0$ then we have the following inequality:

$$
\int_{a}^{b}\left\{x^{(k)}(t)\right\}^{2} d t \leqslant \alpha \int_{a}^{b}\left\{x^{(m)}(t)\right\}^{2} d t+\left(\frac{k}{m \alpha}\right)^{\mathrm{k} / m-k}(1-k / m) \int_{a}^{b}\{x(t)\}^{2} d t
$$

If we let $\mathrm{k}=1, \mathrm{~m}=2$ then our constant has the value $\frac{1}{4 \alpha}$ as compared to the Redheffer value of $\frac{1}{\alpha}+\frac{12}{(\mathrm{~b}-\mathrm{a})^{2}}$.

One may now inquire about the possibility of equality in Corollary 2.1 ; by our previous discussion we see that this is possible if and only if

$$
\lim _{n \rightarrow \infty}\left[1 \stackrel{\max }{\leqslant} \imath\left\{n\left\{\theta^{k} \lambda_{i}^{k}-\alpha \theta^{m} \lambda_{i}^{m}\right\}\right]=\left(\frac{k}{m \alpha}\right)^{k / m-k}\left(1-\frac{k}{m}\right) .\right.
$$

However a brief investigation shows that the above expression is not always satisfied, hence Corollary 2.1 is in general not best possible. A little more work will yield the best inequality.

We notice that the smaller eigenvalues of $P$ approach zero as $1 / n^{2}$ and the positive root of $\theta^{k} t^{k}-\alpha \theta^{m} t^{m}$ exhibits a similar behavior:

$$
\begin{gathered}
\lambda_{n}=0, \lambda_{n-1}=4 \sin ^{2}\left(\frac{\pi}{n}\right) \approx \frac{4 \pi^{2}}{n^{2}}, \lambda_{n-3}=4 \sin ^{2}\left(\frac{2 \pi}{n}\right) \approx \frac{8 \pi^{2}}{n^{2}}, \ldots \\
\operatorname{root}=\frac{(b-a)^{2}}{(n+1)^{2}} \cdot\left(\frac{1}{\alpha}\right)^{1 / m-k} .
\end{gathered}
$$

Hence if we set

$$
L=\left[\frac{b-a}{2 \pi} \cdot\left(\frac{1}{\sqrt{\alpha}}\right)^{1 / m-k}\right]
$$

where [ ] is the greatest integer function, then $L$ is the limiting number of distinct eigenvalues of $P$ which are greater than 0 and less than or equal to the root.

If $L=0$, which occurs when $\alpha>\left(\frac{b-a}{2 \pi}\right)^{2 m-2 k}$, then

$$
\lim _{n \rightarrow \infty}\left[1 \leqslant i \leqslant n\left\{\theta^{k} \lambda_{i}^{k}-\alpha \theta^{m} \lambda_{i}^{m}\right\}\right]=0
$$

yielding the best possible result:

Corollary 2.2. Let $\mathrm{x}(\mathrm{t}), \mathrm{k}, \mathrm{m}$ be as in Corollary 2.1 and let $\alpha>\left(\frac{\mathrm{b}-\mathrm{a}}{2 \pi}\right)^{2 \mathrm{~m}-2 \mathrm{k}}$, then

$$
\int_{\mathrm{a}}^{\mathrm{b}}\left\{\mathrm{x}^{(\mathrm{k})}(\mathrm{t})\right\}^{2} \mathrm{dt} \leqslant \alpha \int_{\mathrm{a}}^{\mathrm{b}}\left\{\mathrm{x}^{(\mathrm{m})}(\mathrm{t})\right\}^{2} \mathrm{dt}
$$


If we add the auxiliary condition $\int_{a}^{b} x(t) d t=0$, then

$$
\lim _{n \rightarrow \infty}\left[1 \leqslant i \leqslant n-1\left\{\theta^{k} \lambda_{i}^{k}-\alpha \theta^{m} \lambda_{i}^{m}\right\}\right]=\left(\frac{2 \pi}{b-a}\right)^{2 k}-\alpha\left(\frac{2 \pi}{b-a}\right)^{2 m} \leqslant 0
$$

and we obtain the best possible result:

COROLlaRY 2.3. Let $\mathrm{x}(\mathrm{t}), \mathrm{k}, \mathrm{m}, \alpha$ be as in Corollary 2.2 and let $\mathrm{x}$ also satisfy $\int_{\mathrm{a}}^{\mathrm{b}} \mathrm{x}(\mathrm{t}) \mathrm{dt}=0$, then

$$
\int_{a}^{b}\left\{x^{(k)}(t)\right\}^{2} d t \leqslant \alpha \int_{a}^{b}\left\{x^{(m)}(t)\right\}^{2} d t+\left\{\left(\frac{2 \pi}{b-a}\right)^{2 k}-\alpha\left(\frac{2 \pi}{b-a}\right)^{2 m}\right\} \cdot \int_{a}^{b}\{x(t)\}^{2} d t .
$$

If $L \geqslant 1$ then there are limiting eigenvalues between zero and the positive root. Hence if we set

$$
J=\left[\frac{b-a}{2 \pi} \cdot\left(\sqrt{\frac{k}{m \alpha}}\right)^{1 / m-k}\right]
$$

then $J$ is the limiting number of distinct eigenvalues of $P$ which are greater than 0 and less than or equal to the maximum of $\theta^{k} t^{k}-\alpha \theta^{m} t^{m}$.

Thus if

$$
\left[\frac{b-a}{2 \pi} \cdot\left(\sqrt{\frac{k}{m \alpha}}\right)^{1 / m-k}\right]=\frac{b-a}{2 \pi} \cdot\left(\sqrt{\frac{k}{m \alpha}}\right)^{1 / m-k}
$$

then

$$
\lim _{n \rightarrow \infty}\left[1 \leqslant i \leqslant n\left\{\theta^{k} \lambda_{i}^{k}-\alpha \theta^{m} \lambda_{i}^{m}\right\}\right]=\left(\frac{k}{m \alpha}\right)^{k / m-k}(1-k / m)
$$

and Corollary 2.1 is best possible. Otherwise we may replace

$$
\left(\frac{k}{m \alpha}\right)^{k / m-k}(1-k / m) \text { by } \max \left\{\left(\frac{2 J \pi}{b-a}\right)^{2 k}-\alpha\left(\frac{2 J \pi}{b-a}\right)^{2 m},\left(\frac{2(J+1) \pi}{b-a}\right)^{2 k}-\alpha\left(\frac{2(J+1) \pi}{b-a}\right)^{2 m}\right\} .
$$

We may summarize the above results by the following best possible inequalities.

Corollary 2.4. If $\mathrm{x}(\mathrm{t}) \in \mathrm{C}^{\mathrm{m}}[\mathrm{a}, \mathrm{b}], 1 \leqslant \mathrm{k}<\mathrm{m}, \mathrm{x}(\mathrm{a})=\mathrm{x}(\mathrm{b}), \mathrm{x}^{\prime}(\mathrm{a})=\mathrm{x}^{\prime}(\mathrm{b}), \ldots, \mathrm{x}^{(\mathrm{m}-1)}(\mathrm{a})=\mathrm{x}^{(\mathrm{m}-1)}(\mathrm{b})$, and if $\alpha>0$ then

$$
\int_{a}^{b}\left\{x^{(k)}(t)\right\}^{2} d t \leqslant \alpha \int_{a}^{b}\left\{x^{(m)}(t)\right\}^{2} d t+H_{k}, m(\alpha) \int_{a}^{b}\{x(t)\}^{2} d t
$$

where

$$
\begin{aligned}
& \mathrm{H}_{\mathrm{k}, \mathrm{m}}(\alpha)=0 \text { for } \alpha>\left(\frac{\mathrm{b}-\mathrm{a}}{2 \pi}\right)^{2 \mathrm{~m}-2 \mathrm{k}}, \\
& \mathrm{H}_{\mathrm{k}, \mathrm{m}}(\alpha)=\left(\frac{\mathrm{k}}{\mathrm{m} \alpha}\right)^{\mathrm{k} / \mathrm{m}-\mathrm{k}}(1-\mathrm{k} / \mathrm{m}) \text { if } \frac{\mathrm{b}-\mathrm{a}}{2 \pi} \cdot\left(\sqrt{\frac{\mathrm{k}}{\mathrm{m} \alpha}}\right)^{1 / \mathrm{m}-\mathrm{k}}
\end{aligned}
$$


is a positive integer, and otherwise

$$
\mathrm{H}_{\mathrm{k}, \mathrm{m}}(\alpha)=\max \left\{\left(\frac{2 \mathrm{~J} \pi}{\mathrm{b}-\mathrm{a}}\right)^{2 \mathrm{k}}-\alpha\left(\frac{2 \mathrm{~J} \pi}{\mathrm{b}-\mathrm{a}}\right)^{2 \mathrm{~m}},\left(\frac{2(\mathrm{~J}+\mathrm{l}) \pi}{\mathrm{b}-\mathrm{a}}\right)^{2 \mathrm{k}}-\alpha\left(\frac{2(\mathrm{~J}+\mathrm{l}) \pi}{\mathrm{b}-\mathrm{a}}\right)^{2 \mathrm{~m}}\right\}
$$

Corollary 2.5. Let $\mathrm{x}(\mathrm{t}), \mathrm{k}, \mathrm{m}, \alpha$ be as in Corollary 2.4 and let $\mathrm{x}$ also satisfy $\int_{\mathrm{a}}^{\mathrm{b}} \mathrm{x}(\mathrm{t}) \mathrm{dt}=0$, then

$$
\int_{a}^{b}\left\{x^{(k)}(t)\right\}^{2} d t \leqslant \alpha \int_{a}^{b}\left\{x^{(m)}(t)\right\}^{2} d t+G_{k}, m(\alpha) \int_{a}^{b}\{x(t)\}^{2} d t
$$

where

$$
\mathrm{G}_{\mathrm{k}, \mathrm{m}}(\alpha)=\left(\frac{2 \pi}{\mathrm{b}-\mathrm{a}}\right)^{2 \mathrm{k}}-\alpha\left(\frac{2 \pi}{\mathrm{b}-\mathrm{a}}\right)^{2 \mathrm{~m}} \text { for } \alpha>\left(\frac{\mathrm{b}-\mathrm{a}}{2 \pi}\right)^{2 \mathrm{~m}-2 \mathrm{k}}
$$

and otherwise

$$
\mathrm{G}_{\mathrm{k}, \mathrm{m}}(\alpha)=\mathrm{H}_{\mathrm{k}, \mathrm{m}}(\alpha)
$$

It is not difficult to see that $H_{k, m}(\alpha)$ and $G_{k, m}(\alpha)$ are piecewise linear functions of $\alpha$, which are monotonic decreasing, and that the jumps in the derivatives of $H_{k, m}$ and $G_{k, m}$ occur for those positive numbers $\alpha_{i}$ which yield

$$
\left(\frac{2 \pi i}{b-a}\right)^{2 k}-\alpha_{i}\left(\frac{2 \pi i}{b-a}\right)^{2 m}=\left(\frac{2 \pi i+2 \pi}{b-a}\right)^{2 k}-\alpha_{i}\left(\frac{2 \pi i+2 \pi}{b-a}\right)^{2 m}
$$

where $i$ is a nonnegative integer. We have $\infty>\alpha_{0}>\alpha_{1}>\ldots>0$ and $\lim _{i \rightarrow \infty} \alpha_{i}=0$. Note that

$$
\int_{a}^{b}\left\{\sin ^{(k)}\left(\frac{2 \pi i t}{b-a}\right)\right\}^{2} d t=\alpha \int_{a}^{b}\left\{\sin ^{(m)}\left(\frac{2 \pi i t}{b-a}\right)\right\}^{2} d t+H_{k, m}(\alpha) \int_{a}^{b}\left\{\sin \left(\frac{2 \pi i t}{b-a}\right)\right\}^{2} d t
$$

for $\alpha_{i} \leqslant \alpha \leqslant \alpha_{i-1}$. This accounts for the piecewise linearity of $H_{k, m}$ and $G_{k, m}$ and will be a great importance in section 4 .

At this stage it is apparent that there is an unlimited number of possible inequalities, in fact every polynomial will give discrete inequalities and polynomials in $\theta t$ yield continuous analogs.

It is known, see for example [1], that if $f(t)$ is represented by a power series with real coefficients and if $A$ is a real symmetric matrix with eigenvalues $\lambda_{1}, \lambda_{2}, \ldots, \lambda_{n}$ which lie strictly within the circle of convergence of the power series for $f(t)$, then $f(A)$ is real symmetric and has eigenvalues $f\left(\lambda_{1}\right), f\left(\lambda_{2}\right), \ldots, f\left(\lambda_{n}\right)$. This result enables us to extend our polynomial inequalities to discrete inequalities on analytic functions.

THEOREм 3. If $\mathrm{x}$ is a periodically extended $\mathrm{n}$-vector and if $\mathrm{f}(\mathrm{t})=\sum_{\mathrm{m}=0}^{\infty} \mathrm{a}_{\mathrm{m}} \mathrm{t}^{\mathrm{m}}$, where the $\mathrm{a}_{\mathrm{m}}$ are real numbers and the series converges on a set containing $[0,4]$ in its interior - if $\mathrm{n}$ is odd then we need only require convergence on a set containing $\left[0,4 \sin ^{2}\left(\left[\frac{\mathrm{n}}{2}\right] \frac{\pi}{\mathrm{n}}\right)\right]$ in its interior - then

$$
\left.\inf _{0} \leqslant 4\{f(t)\}\right](x, x) \leqslant \sum_{m=0}^{\infty} a_{m}\left(x^{(m)}, x^{(m)}\right) \leqslant[0 \leqslant t \leqslant 4\{f(t)\}](x, x) .
$$

The following inequalities are examples of the application of Theorem 3. 
CoROLlaRY 3.1. If $\mathrm{x}$ is a periodically extended $\mathrm{n}$-vector then

$$
\sum_{m=1}^{\infty} \frac{1}{m !}\left(x^{(m)}, x^{(m)}\right) \leqslant\left(e^{4}-1\right)(x, x)
$$

Corollary 3.2. If $\mathrm{x}$ is a periodically extended $\mathrm{n}$-vector and $\theta>0$ then

$$
-(x, x) \leqslant \sum_{m=0}^{\infty}(-1)^{m} \frac{\theta^{2 m+1}}{(2 m+1) !}\left(x^{(2 m+1)}, x^{(2 m+1)}\right) \leqslant(x, x) .
$$

Proof:

$$
\sin t=\sum_{m=0}^{\infty} \frac{(-1)^{m}}{(2 m+1) !} t^{2 m+1} \text { and }|\sin t| \leqslant 1
$$

Corollary 3.3. If $\mathrm{x}(\mathrm{t}) \in \mathrm{C}^{\infty}[\mathrm{b}-\mathrm{a}]$ and $\mathrm{x}(\mathrm{t})$ has period $\mathrm{b}-\mathrm{a}$ then

$$
-\int_{a}^{b}\{x(t)\}^{2} d t \leqslant \sum_{m=0}^{\infty} \frac{(-1)^{m}}{(2 m+1) !} \int_{a}^{b}\left\{x^{(2 m+1)}(t)\right\}^{2} d t \leqslant \int_{a}^{b}\{x(t)\}^{2} d t .
$$

\section{Inequalities of Kolmogoroff Type}

In analysis one frequently wants to obtain inclusion regions for the norms of functions; i.e., if $M$ is in the inclusion region, then there exists a function $f$, from a certain set of functions, with norm of $f$ equal to $M$. Kolmogoroff [4] established a result of this type using the uniform norm over the function set $C^{m}[0, \infty]$. If we set $M_{k}(x)=0 \leqslant t \leqslant \infty\left\{\left|x^{(k)}(t)\right|\right\}(k=0,1,2, \ldots, m)$, then Kolmogoroff [4] gave a necessary and sufficient condition "in order that to a triple of positive numbers $M_{0}, M_{k}, M_{m}(0<k<m)$ there should correspond a function $x(t)$ for which

$$
M_{0}=M_{0}(x), M_{k}=M_{k}(x), M_{m}=M_{m}(x) . "
$$

In this section we will establish a similar result on a triple of positive numbers relative to the square norm, where our set of functions will be $C^{m}[a, b] \cap\left\{x \mid x(a)=x(b), x^{\prime}(a)=x^{\prime}(b), \ldots\right.$, $\left.x^{(m-1)}(a)=x^{(m-1)}(b)\right\}$. We will also add the restriction $\int_{a}^{b} x(t) d t=0$ in order to eliminate the constant function.

If $x(t)$ is an element of our function class, then we set

$$
A_{k}(x)=\int_{a}^{b}\left\{x^{(k)}(t)\right\}^{2} d t \quad(k=0,1,2, \ldots, m)
$$

We may assume without loss of generality that we have normalized $x$ so that $A_{0}(x)=1$. We will establish the following result:

THEOREM 4. In order that to a pair of numbers $\mathrm{a}_{\mathrm{k}}, \mathrm{a}_{\mathrm{m}}$ there should correspond a function $\mathrm{x}(\mathrm{t})$ $\in \mathrm{C}^{\mathrm{m}}[\mathrm{a}, \mathrm{b}] \cap\left\{\mathrm{x} \mid \mathrm{x}(\mathrm{a})=\mathrm{x}(\mathrm{b}), \mathrm{x}^{\prime}(\mathrm{a})=\mathrm{x}^{\prime}(\mathrm{b}), \ldots, \mathrm{x}^{(\mathrm{m}-1)}(\mathrm{a})=\mathrm{x}^{(\mathrm{m}-1)}(\mathrm{b}), \int_{\mathrm{a}}^{\mathrm{b}} \mathrm{x}(\mathrm{t}) \mathrm{dt}=0\right\}$ for which

$$
A_{0}(x)=1, A_{k}(x)=a_{k}, A_{m}(x)=a_{m}
$$


it is necessary and sufficient that

$$
\begin{gathered}
a_{k} \geqslant\left(\frac{2 \pi}{b-a}\right)^{2 k}, a_{m} \geqslant\left(\frac{2 \pi}{b-a}\right)^{2 m}, \text { and } \\
a_{k}-\alpha a_{m} \leqslant G_{k, m}(\alpha) \text { for all } \alpha>0 .
\end{gathered}
$$

\section{Proof of TheORem 4:}

The necessity of the conditions is a direct consequence of Corollaries 1.1 and 2.5.

The proof of the sufficiency will be divided into several cases and we will use the notation of section 3 throughout. We will denote the normalized $\sin \left(\frac{2 \pi i t}{b-a}\right)$ by $S_{i}(t)$. We recall that on the interval $\alpha_{i} \leqslant \alpha \leqslant \alpha_{i-1}$ we have $A_{k}\left(S_{i}\right)-\alpha A_{m}\left(S_{i}\right)=G_{k, m}(\alpha)$.

CASE 1: $a_{k}-\alpha a_{m}=G_{k, m}(\alpha)$ for at least two values of $\alpha$, say $\alpha=t_{1}$ and $\alpha=t_{2}$.

We immediately have that $a_{k}-\alpha a_{m}=G_{k, m}(\alpha)$ for all $\alpha \in\left[t_{1}, t_{2}\right]$. Since we know that the $S_{i}$ are maximizing functions there is an integer $i$ with $\alpha_{i} \leqslant t_{1}<t_{2} \leqslant \alpha_{i-1}$ and $a_{k}-\alpha a_{m}=G_{k, m}(\alpha)$ $=A_{k}\left(S_{i}\right)-\alpha A_{m}\left(S_{i}\right)$ for $\alpha_{i} \leqslant \alpha \leqslant \alpha_{i-1}$. Thus $a_{k}=A_{k}\left(S_{i}\right), a_{m}=A_{m}\left(S_{i}\right)$.

CASE 2: $a_{k}-\alpha a_{m}=G_{k, m}(\alpha)$ for only one value of $\alpha$, say $\alpha=t_{1}$.

We immediately have that $t_{1}=\alpha_{1}$ for exactly one integer $i$. Thus

$$
a_{k}-\alpha_{i} a_{m}=G_{k, m}\left(\alpha_{i}\right)=A_{k}\left(S_{i}\right)-\alpha_{i} A_{m}\left(S_{i}\right)=A_{k}\left(S_{i+1}\right)-\alpha_{i} A_{m}\left(S_{i+1}\right) .
$$

Also since $a_{k}-\alpha a_{m} \leqslant G_{k, m}(\alpha)$ for all $\alpha>0$ we must have $A_{m}\left(S_{i}\right)<a_{m}<A_{m}\left(S_{i+1}\right)$. Thus there exist $b_{i}, b_{i+1}$ with $0<b_{i}, b_{i+1}<1, b_{i}^{2}+b_{i+1}^{2}=1$, and $a_{m}=A_{m}\left(b_{i} S_{i}+b_{i+1} S_{i+1}\right)=b_{i}^{2} A_{m}\left(S_{i}\right)+b_{i+1}^{2} A_{m}\left(S_{i+1}\right)$. [Note that the last equality follows from the orthogonality of $S_{i}$ and all its derivatives to $S_{i+1}$ and all its derivatives.] Now,

$$
\begin{aligned}
A_{k}\left(b_{i} S_{i}+b_{i+1} S_{i+1}\right)-\alpha_{i} a_{m}= & A_{k}\left(b_{i} S_{i}+b_{i+1} S_{i+1}\right)-\alpha_{i} A_{m}\left(b_{i} S_{i}+b_{i+1} S_{i+1}\right) \\
& =b_{i}^{2}\left[A_{k}\left(S_{i}\right)-\alpha_{i} A_{m}\left(S_{i}\right)\right]+b_{i+1}^{2}\left[A_{k}\left(S_{i+1}\right)-\alpha_{i} A_{m}\left(S_{i+1}\right)\right]=\left(b_{i}^{2}+b_{i+1}^{2}\right)\left[a_{k}-\alpha_{i} a_{m}\right] .
\end{aligned}
$$

Hence $a_{k}=A_{k}\left(b_{i} S_{i}+b_{i+1} S_{i+1}\right)$.

CASE 3: $a_{k}-\alpha a_{m}<G_{k, m}(\alpha)$ for all $\alpha>0$ and $a_{m} \geqslant\left(\frac{4 \pi}{b-a}\right)^{2 m}=A_{m}\left(S_{2}\right)$.

We know that there is exactly one integer $i \geqslant 2$ with $\left(\frac{2 i \pi}{b-a}\right)^{2 m} \leqslant a_{m}<\left(\frac{2(i+2) \pi^{2 m}}{b-a}\right)$ or $A_{m}\left(S_{i}\right)$ $\leqslant a_{m}<A_{m}\left(S_{i+1}\right)$. If we repeat the construction of Case 2 we can find $b_{i}$ and $b_{i+1}$ with $a_{m}=A_{m}\left(b_{i} S_{i}\right.$ $\left.+b_{i+1} S_{i+1}\right)$ and since $a_{k}-\alpha_{i} a_{m}<G_{k, m}\left(\alpha_{i}\right)=A_{k}\left(b_{i} S_{i}+b_{i+1} S_{i+1}\right)-\alpha_{i} A_{m}\left(b_{i} S_{i}+b_{i+1} S_{i+1}\right)=A_{k}\left(b_{i} S_{i}\right.$ $\left.+b_{i+1} S_{i+1}\right)-\alpha_{i} a_{m}$ we have

$$
a_{k}<A_{k}\left(b_{i} S_{i}+b_{i+1} S_{i+1}\right) .
$$

By our conditions on $a_{k}$ and $a_{m}$ there is an integer $j>i+1$ and an $\bar{\alpha}>0$ such that $A_{k}\left(S_{j}\right)$ $-\bar{\alpha} A_{m}\left(S_{j}\right)=A_{k}\left(S_{1}\right)-\bar{\alpha} A_{m}\left(S_{1}\right)<a_{k}-\bar{\alpha} a_{m}$. Now $A_{m}\left(S_{1}\right)<A_{m}\left(S_{i}\right) \leqslant a_{m}<A_{m}\left(S_{i+1}\right)<A_{m}\left(S_{j}\right)$, hence there are $b_{1}, b_{j}$ with $a_{m}=A_{m}\left(b_{1} S_{1}+b_{j} S_{j}\right)$ and since

$$
a_{k}-\bar{\alpha} a_{m}>G_{k, m}(\bar{\alpha})=A_{k}\left(b_{1} S_{1}+b_{j} S_{j}\right)-\bar{\alpha} A_{m}\left(b_{1} S_{1}+b_{j} S_{j}\right)=A_{k}\left(b_{1} S_{1}+b_{j} S_{j}\right)-\bar{\alpha} a_{m}
$$


we have

$$
a_{k}>A_{k}\left(b_{1} S_{1}+b_{j} S_{j}\right)
$$

By the orthogonality of $b_{1} S_{1}+b_{j} S_{j}$ and $b_{i} S_{i}+b_{i+1} S_{i+1}$ there are constants $c$ and $d$ with $c^{2}+d^{2}=1$ for normalization and

$$
\begin{aligned}
& a_{m}=A_{m}\left(c b_{1} S_{1}+C B_{j} S_{j}+d b_{i} S_{i}+d b_{i+1} S_{i+1}\right), \\
& a_{k}=A_{k}\left(c b_{1} S_{1}+c b_{j} S_{j}+d b_{i} S_{i}+d b_{i+1} S_{i+1}\right) .
\end{aligned}
$$

CASE 4: $a_{k}-\alpha a_{m}<G_{k, m}(\alpha)$ for all $\alpha$ and $a_{m}<\left(\frac{4 \pi}{b-a}\right)^{2 m}=A_{m}\left(S_{2}\right)$.

If we repeat the process of Cases 2 and 3 we can find $b_{1}, b_{2}$ such that $a_{m}=A_{m}\left(b_{1} S_{1}+b_{2} S_{2}\right)$ and $a_{k}<A_{k}\left(b_{1} S_{1}+b_{2} S_{2}\right)$.

We cannot simply repeat the process of Case 3 because $b_{1} S_{1}+b_{2} S_{2}$ will not be orthogonal to $b_{1}^{\prime} S_{1}+b_{2}^{\prime} S_{2}$. However we note that the normalized multiple of $\cos \left(\frac{2 \pi t}{b-a}\right)$, which we denote by $C_{1}(t)$, also satisfies $A_{k}\left(C_{1}\right)-\alpha A_{m}\left(C_{1}\right)$ for $\alpha_{1} \leqslant \alpha \leqslant \alpha_{0}$ and is orthogonal to all the $S_{i}$. Hence we can find $c_{1}, c_{j}$ such that

$$
a_{m}=A_{m}\left(c_{1} C_{1}+c_{j} S_{j}\right) \text { and } a_{k}>A_{k}\left(c_{1} C_{1}+c_{j} S_{j}\right)
$$

and we continue as in Case 3 .

Thus we have proven Theorem 4.

\section{References}

[1] S. Afriat, Analytic functions of matrices, Proc. Camb. Phil. Soc. 55, 51-56 (1956).

[2] K. Fan, O. Taussky, J. Todd, Discrete analogs of inequalities of Wirtinger, Monatshefte für Math. 59, 73-90 (1955).

[3] I. Halperin and H. Pitt, Integral inequalities connected with differential operators, Duke Math. J. 4, 613-625 (1938).

[4] A. Kolmogoroff, On inequalities between the upper bounds of the successive derivatives of an arbitrary function on an infinite interval, Amer. Math. Soc. Translation No. 4, 1949.

[5] W. Müller, Über eine Ungleichung zwischen den Normen von $f, f^{\prime}$ und $f^{\prime \prime}$, Math. Zeitschr. 78, 420-422 (1962).

[6] L. Nirenberg, Remarks on strongly elliptic partial differential equations, Appendix, Comm. Pure and Appl. Math. 8, 649-675 (1955).

[7] R. Redheffer, Über eine beste Ungleichung zwischen den Normen von $f, f^{\prime}, f^{\prime \prime}$, Math. Zeitschr. 80, 390-397 (1963).

[8] D. E. Rutherford, Some continuant determinants arising in physics and chemistry, I., Proc. Royal Soc. Edinburgh, 52A, 229-236 (1947).

(Paper 70B3-184) 


\section{Publications of the National Bureau of Standards}

\section{Selected Abstracts}

A note on the numerical evaluation of thermal radiation characteristics of diffuse cylindrical and conical cavities, B. A. Peavy, J. Res. NBS 70C (Engr. and Instr.) No. 2, 139-147 (Apr.-June 1966).

Presented are methods that avoid the need to employ an extrapolation technique in the region of the critical points for evaluation of the apparent emissivity of diffuse cylindrical and conical cavities. The methods involve appropriate substitutions in the integrands of integral equations that are used in analytical solutions for determining the thermal radiation characteristics of diffuse and conical cavities. Equations for either isothermal or nonisothermal surface temperature conditions are provided in a direct form for computations. Numerical results are presented for a general linear temperature distribution along the length of a cylindrical cavity. The method is equally applicable for the solution of other problems in integral equations where discontinuities are encountered.

Two-dimensional probability distribution in a turbulent field, F. N. Frenkiel and P. S. Klebanoff, Phys. Fluids 8, No. 12, 2291-2293 (Dec. 1965).

Using high speed computing techniques measurements were made for the first time of a two-dimensional probability distribution in a turbulent field generated by a grid in a wind tunnel. The twodimensional probability distribution of simultaneous turbulent velocities at two points separated transversely to the mean flow (in the initial stage of decay) is presented, and the departure from the customarily assumed Gaussian distribution is shown.

Propagation of electromagnetic pulses in terrestrial waveguides, J. R. Wait, IEEE Trans. Ant. Prop. AP-13, No. 6, 904-918 (Nov. 1965).

The propagation of electromagnetic waves over the earth's surface is considered under transient conditions. The source is taken to be a vertical electric dipole whose current moment is suddenly established. The build-up of the radiated field is calculated under various assumed conditions. It is shown, even in the absence of an ionospherically reflected wave, that the influence of earth curvature has a pronounced effect on the distortion of the original pulse shape. For great distances (i.e., $d>2000 \mathrm{~km}$ ), it is found to be more convenient to regard the field as a sum of modes. Particular attention is given to the transient characteristics of the dominant mode as a function of the source waveform.

The analysis, synt hesis, and description of biological images, L. E. Lipkin, W. C. Watt, and R. A. Kirsch, Ann. N.Y. Acad. Sci. 128, No. 3, 984-1012 (Jan. 31, 1966).

There may be distinguished two approaches to characterizing the properties of biological images: the statistical approach traditionally used for mechanized image-processing, and the articular approach generally used among biologists. We discuss both approaches, but focus attention on the second, for we hold that an articular approach allows the expression of much that is effectively impossible to express in the form of numerical measurements; and we know of no inherent reason why a computer cannot deal with information of a nonquantitative nature.

The articulation of biological images necessarily takes place on two fronts: the imposition of an articular structure on the image itself; and the expression of this construal in English sentences. We will study both kinds of articulation, and we will suggest how they may be brought together, in the form of linked pictorial and linguistic grammars. The computer system which this paper envisions will be able to analyze a presented image with respect to a pictorial grammar, and to formulate and accept descriptions of that image, in English sentences, with respect to a linguistic grammar. It will be able to present pictorial instances of English descriptions, and in other ways to respond to English directives.

Status of linear relations among heats of transport, R. E. Howard and A. B. Lidiard, J. Chem. Phys. 43, No. 11, 4158-4160 (Dec. 1, 1965).

It is shown that in situations where the fluxes of the various components of a system are not linearly independent, previously derived linear relations among the heats of transport contain no physical information, but serve only to complete the definition of these quantities. Other defining equations are possible but physical predictions are unaffected by the choice so presented. This resolves the paradox of the apparent inconsistency of these linear relations with kinetic theories of heats of transport.

\section{Other NBS Publications}

J. Res. NBS 70A, (Phys. and Chem.), No. 3, (May-June 1966), $\$ 1.00$.

Thermal relaxation of Brillouin scattering in liquids. R. D. Mountain. Density of polyethylene crystals grown from solution. G. M. Martin and E. Passaglia.

Mechanical relaxation in polyethylene crystallized with various degrees of lamellar orientation. J. M. Crissman and E. Passaglia.

Pentafluorophenyl aklyl and vinyl ethers. W. J. Pummer and L. A. Wall.

Calibration of germanium resistors at low temperatures $\left(2-20^{\circ}\right.$ Kelvin). G. Cataland and H. H. Plumb.

Dissociation pressure of aluminum carbide using a rotating Knudsen cell. E. R. Plante and C. H. Schreyer.

Determination of intermolecular potential functions from macroscopic measurements. M. Klein.

J. Res. NBS 70C, (Engr. and Instr.), No. 2, (Apr.-June 1966), 75 cents.

Design and statistical procedures for the evaluation of an automatic gamma-ray point-source calibrator. S. B. Garfinkel, W. B. Mann, and W. J. Youden.

Testing of lenses with the wave front reversing interferometer. K. Muraoka.

Ellipsoidal mirror reflectometer. S. Thomas Dunn, J. C. Richmond, and J. A. Wiebelt.

Reference tables for the Pt-30 percent Rh versus $\mathrm{Pt}-6$ percent $\mathrm{Rh}$ thermocouple. G. W. Burns and J. S. Gallagher.

Coaxial power meter calibration using a waveguide standard. G. F. Engen.

A note on the numerical evaluation of thermal radiation characteristics of diffuse cylindrical and conical cavities. B. A. Peavy. (See above abstract.)

J. Res. NBS 70C, (Engr. and Instr.), No. 3, (July-Sept. 1966), $\$ 1.00$.

Some harmonic properties of an oscillating Fabry-Perot interferometer. M. Gadsden and H. M. Williams.

Precise reflection coefficient measurements with an untuned reflectometer. W. E. Little and D. A. Ellerbruch.

A versatile ratio instrument for the high ratio comparison of voltage or resistance. A. E. Hess.

Console for the rapid and precise comparison of volt boxes. P. H. Lowrie, Jr.

Corrosion rates of binary alloys of nickel and iron measured by polarization methods. W. J. Schwerdtfeger.

The effect of cold-drawing on the creep behavior of a nickel-4.2 percent aluminum alloy. W. D. Jenkins and W. A. Willard.

Magnetic transformation and the influence of plastic strain on the shear modulus of Fe-Cr-Ni alloys. R. P. Mikesell and R. P. Reed. 
NBS standard frequency and time services, NBS Misc. Publ. 236, 1966 edition (1966), 15 cents (supersedes previous editions).

Statistical association methods for mechanized documentation. Symposium Proceedings Washington 1964, M. E. Stevens, V. E. Giuliano, and L. B. Heilprin, NBS Misc. Publ. 269 (Dec. 15, 1965), $\$ 2.75$.

Report of the 50th National Conference on Weights and Measures 1965, NBS Misc. Publ. 272 (Apr. 1, 1966), \$1.00.

Photonuclear data index, NBS Misc. Publ. 277 (Apr. 1, 1966), 55 cents.

Bibliography on atomic transition probabilities, B. W. Glennon and W. L. Wiese, NBS Misc. Publ. 278 (Apr. 22, 1966), 55 cents, (supersedes Mono. 50).

Radio meteorology, B. R. Bean and E. J. Dutton, NBS Mono. 92, (March 1, 1966), \$2.75.

OMNITAB. A computer program for statistical and numerical analysis, J. Hilsenrath, G. G. Ziegler, C. G. Messina, P. J. Walsh, and R. J. Herbold, NBS Handb. 101 (March 4, 1966), \$3.00.

Copper wire tables, NBS Handb. 100 (Feb. 21, 1966), 50 cents, supersedes Circ. 31

List of errata to accompany the first, second, and third printings of NBS Applied Mathematics Series 55, Handbook of Mathematical Functions with Formulas, Graphs, and Mathematical Tables, ed. M. Abramowitz and I. A. Stegun (April, 1966). This errata is free to holders of AMS55, upon request from the Publications Section, A617 Administration Building, National Bureau of Standards, Washington, D.C. 20234.

Doors as barriers to fire and smoke, H. Shoub and D. Gross, Bldg. Sci. Series 3, (Mar. 25, 1966), 15 cents.

Quarterly radio noise data September, October, November, 1964, W. Q. Crichlow, R. T. Disney, and M. A. Jenkins, NBS Tech. Note 18-24 (Feb. 10, 1966), 50 cents. (Formerly the Central Radio Propagation Laboratory of the National Bureau of Standards, now Environmental Science Services Administration, Boulder, Colo.)

Procedures for precise determination of thermal radiation properties, November 1963 to October 1964, J. C. Richmond, S. T. Dunn, D. P. DeWitt, and W. D. Hayes, Jr., NBS Tech. Note 267, (Dec. 17, 1965), 45 cents.

Earth's field static calibrator for accelerometers, P. S. Lederer and J. S. Hilten, NBS Tech. Note 269 (Feb. 1, 1966), 20 cents.

Nuclear and radiation standards of importance to the National Atomic Energy Program, H. W. Koch, J. H. Donnert, W. W. Havens, Jr., G. L. Rogosa, and L. Rosen, NBS Tech. Note 283 (Mar. 31, 1966), 35 cents.

An outline for cooperative action on the determination of $\mathrm{x}$-ray mass attenuation coefficients in the wavelength range from 0.5 to $100 \AA$ (25 to $0.12 \mathrm{keV}$ ), K. F. J. Heinrich, NBS Tech. Note 284 (Feh. 21, 1966), 15 cents.

Computation of the permeability and permittivity of a relatively small ring sample in a toroidal coil, E. G. Johnson, Jr., NBS Tech. Note 311 (Jan. 25, 1966), 30 cents.

Disclosures on magnetic tape handler focus detector, multi-pen recorder, signal averaging filter, electrostatic RMS voltmeter, back-up ring for O-rings, and low temperature solid state thermometer, ed. D. Robbins and A. J. Englert, NBS Tech. Note 287 (Apr. 8, 1966), 25 cents.

An atlas of solar flare effects in the ionosphere observed with a high-frequency Doppler technique, September 1960-December 1962, D. M. Baker, NBS Tech. Note 326 (Dec. 1, 1965), 60 cents. (Formerly the Central Radio Propagation Laboratory of the National Bureau of Standards, now Environmental Science Services Administration, Boulder, Colo.)

The seasonal variation of nightglow NaI 5890-96 A, [01] $5577 \mathrm{~A}$ and [01] $6300 \mathrm{~A}$ in the tropics, L. L. Smith and R. W. Owen, NBS Tech. Note 329 (Jan. 10, 1966), 35 cents. (Formerly the Central Radio Propagation Laboratory of the National Bureau of Standards, now Environmental Science Services Administration, Boulder, Colo.)

Computations of the antenna cut-back factor for LF radio waves, D. C. Hyovalti, NBS Tech. Note 330 (Nov. 26, 1965), 30 cents. (Formerly Central Radio Propagation Laboratory of the National Bureau of Standards, now Environmental Science Services Administration, Boulder, Colo.)

A $100 \mathrm{KW} \mathrm{2-25} \mathrm{Mc/s} \mathrm{distributed} \mathrm{amplifier,} \mathrm{designed} \mathrm{for} \mathrm{use} \mathrm{with}$ $10 \mathrm{~kW}$ ionospheric sounders, W. B. Harding, M. W. Woodward, and J. C. Carroll, NBS Tech. Note 331 (Feb. 15, 1966), 20 cents. (Formerly Central Radio Propagation Laboratory of the National Bureau of Standards, now Environmental Science Services Administration, Boulder, Colo.)

A review of zinc oxide-eugenol type filling materials and cements, G. M. Brauer, Rev. Belge. Med. Dent.-Belg. Tijds. Tandheelk 20, No. 3, 323-364 (1965).

Application of a high-intensity, multi-slit Raleigh interferometer to sedimentation studies, I. H. Billick and R. J. Bowen, J. Phys, Chem. 69, 4024-4030 (1965).

Crystal and molecular structure of $\mathrm{C}_{4} \mathrm{~B}_{20} \mathrm{H}_{22}$, bis (o-dodecacarborane), L. H. Hall, A. Perloff, F. A. Mauer, and S. Block, J. Chem. Phys. 43, No. 11, 3911-3917 (Dec. 1965).

Dissociation of ammonium ion in methanol-water solvents, M. Paabo, R. G. Bates, and R. A. Robinson, J. Phys. Chem. 70, No. 1, 247251 (1966).

Electrochemistry, W. J. Hamer, Book, Encyclopedia of Physics, pp. 200-203 (Reinhold Publ. Corp., New York, N.Y., 1966).

Kinetics of the hydroxyl radical in aqueous solution, F. Sicilio, R. E. Florin, and L. A. W all, J. Phys. Chem. 70, No. 47, 47-52 (Jan. 1966).

Manganese-hydrogen bond distance in $\mathrm{HMn}(\mathrm{CO})_{5}$, T. C. Farrar, W. Ryan, A. Davison, and J. W. Faller, J. Am. Chem. Soc. 88, 184 (Jan. 5, 1966).

Matrix-isolation infrared spectrum of the free radical CCO, M. E. Jacox, D. E. Milligan, N. G. Moll, and W. E. Thompson, J. Chem. Phys. 43, No. 10, 3734-3746 (Nov. 1965).

Matrix-isolation infrared spectrum of the free radical $\mathrm{NH}_{2}, \mathrm{D}$. E. Milligan and M. E. Jacox, J. Chem. Phys. 43, No. 12, 3487-4493 (Dec. 15, 1965).

Matrix isolation study of the photolysis of cyanogen azide. The infrared and ultraviolet spectra of the free radical NCN, D. E. Milligan, M. E. Jacox, and A. Bass, J. Chem. Phys. 43, No. 9, 3149-3160 (Nov. 1, 1965).

Patterns of thinking in searching patent applications by manual and machine-assisted methods, J. R. Cornog and P. P. Ellis, J. Chem. Doc. 5, 215-225 (Nov. 1965).

Photolysis of cyclobutane at photo energies below and above the ionization energy, R. D. Doepker and P. Ausloos, J. Chem. Phys 43, No. 11, 3814-3819 (Dec. 1, 1965).

Separation of pyrenediones by column chromatography, A. J. Fatiadi, J. Chromatog. 20, 319-324 (1965).

The effect of gamma-irradiation on a polyamide, V. J. Kransnansky, M. S. Parker, and R. E. Florin, J. Phys. Chem. 70, No. 1, 40-46 (Jan. 1966).

The thermal degradation mechanism of polystryene, L. A. Wall, S. Straus, J. H. Flynn, D. McIntyre, and R. Simha, J. Phys. Chem. 70, No. 1, 53-62 (Jan. 1966).

Zone refiner with temperature control, F. Ordway, Anal. Chem. 37, 1178-1180 (Aug. 1965).

A simple method for making stereoscopic drawings, F. Ordway, Am. Mineralogist 50, 1496-1498(1965).

A system for accurate direct and alternating voltage measurements, F. L. Hermach, J. E. Griffin, and E. S. Williams, IEEE Trans. Instr. Meas. IM-14, No. 4, 215-224 (Dec. 1965).

Effect of surface roughness on emittance of non-metals, J. C. Richmond, J. Opt. Soc. Am. 56, No. 2, 253-254, (Feb. 1966).

Comparison of uncertainty ellipses calculated from two spectrophotometric colorimetry methods by an automatic-computer program, I. Nimeroff, J. Opt. Soc. Am. 56, No. 2, 230-237 (Feb. 1966).

An international comparison of current-ratio standards at audio frequencies, B. L. Dunfee and W. J. M. Moore, IEEE Trans. Instr. Meas. IM-14, No. 4, 172-177 (Dec. 1965).

The design and performance of multirange current transformer standards for audio frequencies, B. L. Dunfee, IEEE Trans. Instr. Meas. IM-14, No. 4, 190-204 (Dec. 1965).

Color, D. B. Judd, Book, Encyclopedia of Physics, pp. 113-116 (Reinhold Publ. Corp., New York, N.Y., 1966).

Deposition of energy by neutrons in spherical cavities, R. S. Caswell, Radiation Res. 27, No. 1, 92-107 (Jan. 1966).

High-frequency elastic moduli of simple fluids, R. Zwanzig and R. D. Mountain, J. Chem. Phys. 43, No. 12, 4464-4471 (Dec. 15, 1965).

Initiation of spherulite growth: The case of concurrent homogeneous and heterogeneous nucleation, F. Gornick, J. Appl. Phys. 36, No. 10, 3012-3014 (Oct. 1965). 
Limits on calorimetric residual entropies of glasses, A. B. Bestul and S. S. Chang, J. Chem. Phys. 43, No. 12, 4532-4533 (Dec. $15,1965)$.

Nuclear moments of $\mathrm{Pm}^{147}$, J. Reader, Phys. Rev. 141, No. 3, 1123-1128 (Jan. 1966).

Erratum-Nuclear magnetic moment of $\operatorname{Pr}^{141}$ from the hyperfine structure of doubly ionized praseodymium, J. Reader and J. Sugar, Phys. Rev. 140, No. 7AB, AB3 (Dec. 27, 1965).

Photometry, L. E. Barbrow, Book, Encyclopedia of Physics, pp. 516-519 (Reinhold Publ. Corp., New York, N.Y. 1966).

Relativistic electron precipitation into the mesosphere at subauroral latitudes, D. K. Bailey and M. A. Pomerantz, J. Geophys. Res. 70, No. 23, 5823-5830 (Dec. 1, 1965).

Absolute-velocity mossbuaer spectrometer, J. J. Spijkerman and F. C. Ruegg, Trans. Am. Nucl. Soc. 8, No. 2, 344 (1966).

Adhesive bonding of various materials to hard tooth tissues. V. The effect of a surface-active comonomer on adhesion to diverse substrates, R. L. Bowen, J. Dental Res. 44, No. 6, 1369-1373 (Nov.-Dec. 1965).

A simple device for adjusting dental interferometers, H. J. Caul and J. W. Kumpula, J. Dental Res. 44, No. 6, 1412 (Nov.-Dec. 1965). Chemical analysis, G. M. Brauer and G. M. Kline, Encyclopedia of Polymer and Technology 3, 633-665 (John Wiley \& Sons, Inc., New York, N.Y., 1965)

Determination of trace amounts of cadmium and silver by substoichiometric radioisotopic dilution analysis, A. R. Landgrebe, L. T. McClendon, and J. R. DeVoe, Trans. Am. Nucl. Soc. 8, No. 2, 315-316 (1966).

Dissociation of acetic acid- $d_{3}$ in aqueous solution and related isotope effects from 0 to $50^{\circ}$, M. Paabo, R. G. Bates, and R. A. Robinson, J. Phys. Chem. 70, 540-543 (1966).

Magnesium isotope ratios in natural samples, E. J. Catanzaro and T. J. Murphy, J. Geophys. Res. 71, No. 4, 1271-1274 (Feb. 15, 1966).

NMR studies of inorganic fluorides. I. High-resolution ${ }^{19} \mathrm{~F}$ spectra of $\mathrm{Si}_{2} \mathrm{~F}_{6}$ and $\left(\mathrm{SiF}_{3}\right)_{2} \mathrm{O}$, R. B. Johannesen, R. C. Farrar, F. E. Brinckman, and T. D. Coyle, J. Chem. Phys. 44, No. 3, 962-964 (Feb. 1, 1966).

On the limiting shape of the distribution function of lengths of a single polymer molecule with excluded-volume effects, J. Mazur, J. Chem. Phys. 43, No. 12, 4354-4356 (Dec. 15, 1965).

Viscosity and density of boron trioxide, A. Napolitano, P. B. Macedo, and E. T. Hawkins, J. Am. Ceramic Soc. 48, No. 12, 613-616 (1965).

Comparison of xenon and carbon arcs as radiation sources for laboratory weathering of asphalts, K. G. Martin, P. G. Campbell, and J. R. Wright, Am. Soc. Testing Mater. Proc. 65, 809-830 (1965).

Proposed standard for measuring and reporting physical properties of optical materials, G. W. Cleek, F. J. P. Consitt, and W. D Lawson, Infrared Phys. 5, 141-160 (Dec. 1965).

Techniques for detection of high-altitude nuclear explosions, A. G. Jean, C. E. Hornback, R. H. Doherty, J. R. Winkelman, and R. T. Moore, Proc. IEEE 53, No. 12, 2088-2098 (Dec. 1965).

The low temperature removal of small quantities of nitrogen or methane from hydrogen gas by physical adsorption on a synthetic zeolite, A. J. Kidnay and M. J. Hiza, A. I. Ch. E. J. 12, No. 1, 58-64 (Jan. 1966).

Departures from local thermal equilibrium in a magnetically-driven shock wave, K. L. Eckerle and R. W. P. McWhirter, Phys. Fluids 9, No. 1, 81-89 (Jan. 1966).

Effect of normal-fluid motion on third sound in liquid-helium films, G. L. Pollack, Phys. Rev. 143, No. 1, 103-109 (Mar. 4, 1966).

Mossbauer line broadening in $\mathrm{SnO}_{2}, \mathrm{R}$. H. Herber and J. Spijkerman, J. Chem. Phys. 42, No. 12, 4312-4314 (June 15, 1966).

Multivibrator provides bidirectional output pulses, F. C. Ruegg, Electronics 38, No. 17, 87 (Aug. 8, 1965).

Precision of cubic lattice parameter measurements by the Kossel technique, H. Yakowitz, Trans. Symp. Electron Probe Analysis, Oct. 12-15, 1964, Wash., D.C., pp. 417-438 (John Wiley \& Sons, Inc., New York, N.Y., 1966).

Radiative corrections. I. High-energy bremsstrahlung and pair production, K. Mork and H. Olsen, Phys. Rev. 140, No. 6B, B1661-B1674 (Dec. 20, 1965).
Random-walk calculations of diffusion coefficients, R. E. Howard, Proc. 5th Intern. Symp. Reactivity of Solids, Munich, Germany, 1964, pp. 250-255 (Elsevier Publ. Co., Amsterdam, The Netherlands, 1965).

Relative transition probabilities for prominent Ni I and Ni II lines in the near-ultraviolet, G. D. Bell, D. R. Paquette, and W. L. Wiese, Astrophys. J. 143, No. 2, 559-572 (Feb. 1966).

Resonances in the elastic and inelastic electron scattering from $\mathrm{N}_{2}$, H. G. M. Heideman, C. E. Kuyatt, and G. E. Chamberlain, J. Chem. Phys. 44, No. 1, 355-358 (Jan. 1, 1966).

Stress-strain properties of textile yarns subjected to rifle bullet impact, C. A. Fenstermaker and J. C. Smith, J. Appl. Polymer Sci. 1, 125-146 (1965).

The correction factor for fast neutron reactions on sulfur and oxygen in the manganous-sulfate-bath calibration of neutron sources, W. M. Murphey, Nucl. Instr. Methods 37, No. 1, 13-21 (1965).

The effect of humidity on ionization measurements with cavity and free-air chambers, T. P. Loftus, B. Petree, and J. T. Weaver, Jr., Radiology 86, No. 1, 149 (Jan. 1966).

An investigation of concentric ring antennas with low sidelobes, C. O. Stearns and A. C. Stewart, IEEE Trans. Ant. Prop. AP-13, No. 6, 856-863 (Nov. 1965).

On radiation of electromagnetic and electroacoustic waves in plasma. Part II, J. R. Wait, Appl. Sci. Res. 12, Sect. B, 130-138 (1965).

Adsorption isotherms for polymer chains adsorbed from theta solvents, C. A. J. Hoeve, J. Chem. Phys. 44, No. 4, 1505-1509 (Feb. 15, 1966).

Critical scattering of the perfluoroheptane-iso-octane system, G. W. Brady, D. McIntyre, M. E. Myers, Jr., and A. M. Wims, J. Chem. Phys. 44, No. 5, 2197-2198 (Mar. 1, 1966).

Polymer property-structure studies at the National Bureau of Standards; thermal stability, G. M. Kline, Proc. European Plastics Congress, Milano, Italy, Sept. 20-23, 1964.

Polymers and telomers of perfluoro-1, 4-pentadiene, J. E. Fearn, D. W. Brown, and L. A. Wall, J. Polymer Sci. 4, Pt. A-1, 131-140 (1966).

The vaterite-type $\mathrm{ABO}_{3}$ rare-earth borates, W. F. Bradley, D. L. Graf, and R. S. Roth, Acta Cryst. 20, Pt. 2, 283-287 (Feb. 1966).

Accuracy and precision of standards and measurements, W. A. Wildhack, Acta Imeko 4, 63-81 (1964).

Time-resolved electrical measurements in high current discharges, E. C. Cassidy, S. W. Zimmerman, and K. K. Neuman, Rev. Sci. Instr. 37, No. 2, 210-214 (Feb. 1966).

Experimental verification of superachromatism, R. E. Stephens, J. Opt. Soc. Am. 56, No. 2, 213-214 (Feb. 1966).

Force fields for the boron trihalides, I. W. Levin and S. Abramowitz, J. Chem. Phys. 43, No. 12, 4213-4222 (Dec. 15, 1965).

Interpretation of Brillouin spectra, R. D. Mountain, J. Chem. Phys. 44, No. 2, 832-833 (Jan. 15, 1966).

Isotopic effects in the $\nu_{3}$ fundamental of matrix-isolated $\mathrm{BCl}_{3}, \mathrm{~J}$. J. Comeford, S. Abramowitz, and I. W. Levin, J. Chem. Phys. 43, No. 12, 4536-4537 (Dec. 15, 1965).

On the quantum-mechanical pair-correlation function of ${ }^{4} \mathrm{He}$ gas at low temperatures, S. Y. Larsen, K. Witte, and J. E. Kilpatrick, J. Chem. Phys. 44, No. 1, 213-220(Jan. 1, 1966).

Spectral distribution of scattered light in a simple fluid, R. D. Mountain, Rev. Mod. Phys. 38, No. 1, 205-214 (Jan. 1966).

Spin-lattice relaxation in some rare-earth trichlorides, B. W. Mangum and R. P. Hudson, J. Chem. Phys. 44, No. 2, 704-713 (Jan. 15, 1966).

The crystal structure of the strontium and lead tetraborates, $\mathrm{SrO}$ $\cdot 2 \mathrm{~B}_{2} \mathrm{O}_{3}$ and $\mathrm{PbO} \cdot 2 \mathrm{~B}_{2} \mathrm{O}_{3}$, A. Perloff and S. Block, Acta Cryst. 20, pt. 2, 274-279 (Feb. 1966).

Search methods used with transistor patent applications, J. R. Cornog and H. L. Bryan, Jr., IEEE Spectrum, pp. 116-121 (Feb. 1966).

*Publications for which a price is indicated are available by purchase from the Superindent of Documents, U.S. Government Printing Office, Washington, D.C. 20402 (foreign postage, one-fourth additional). The NBS nonperiodical series are also available from the Clearinghouse for Federal Scientific and Technical Information, Springfield, Va. 22151. Reprints from outside journals and the NBS Journal of Research may often be obtained directly from the authors. 